\title{
EXPERIMENTAL INVESTIGATION ON DIRECT EVAPORATIVE AIR COOLER PERFORMANCE WITH CELLULOSIC PADS
}

\author{
Alaa Ruhma Al-Badri, \\ Mechanical Engineering Department, College of Engineering, University of Wasit, Wasit, Iraq. \\ E-mail: albadria@uowasit.edu.iq
}

Received on 5 October 2017 Accepted on 31 October 2017 Published on 15 February 2018 DOI: $10.30772 / q j e s . v 10 i 4.502$

\begin{abstract}
Evaporative cooling is an economic and environment-friendly technique for air cooling. This technique may involve air cooling with humidification (direct evaporative cooling) or sensible air cooling only (indirect evaporative cooling). In this study, the saturation efficiency of direct evaporative cooling (DEC) was investigated with rigid media cellulose (RMC) pads and compared with that of wood straw pads. Face air velocity on pads was varied between 0.5 and $3.0 \mathrm{~m} \cdot \mathrm{s}^{-1}$. The time change of ambient air dry-and wetbulb temperatures, water temperature, and outlet air dry-bulb temperature were measured. For cellulosic pad, the experimental data showed that the saturation efficiency reached $71 \%$ of its steady state value in the first 100 seconds of operation and the final steady state value was reached after 600 seconds. The saturation efficiency decreases with the increase in the air velocity. It could be shown that the DEC is more efficient with wood straw pads compared to RMC pads. Predicted data using the published literature underestimated the saturation efficiency of DEC by about $18 \%$.
\end{abstract}

Keywords: RMC pads, Wood straw pads, Evaporative cooling, Saturation efficiency, Adiabatic saturation.

\section{INTRODUCTION}

Direct evaporative air coolers are wildly used in dry and hot weather regions because they are simple in design, saving in power, and friendly to environment. As a result of the remarkable increase in the energy consumption and the continuous depletion of natural energy recourses, evaporative cooling technique is considered to be a potential and promising alternative to mechanical-refrigeration air cooling systems. There are two different techniques for evaporative cooling which are direct and indirect depending on the contact method between air and water. For the indirect evaporation, the two fluids exchange sensible heat via a heat exchanger walls without affecting the air moisture content. In direct evaporation cooling, air is cooled by water evaporation only during a humidification process. The humidification process occurs in a cooling medium (pad) which provides cross flow passages. Water drops to bottom of the pad due to gravity while air flow crosses the direction of water flow. The performance of direct evaporative cooling is dependent on operating and configuration parameters. The operating parameters include the weather condition, water inlet temperature, and air-water mass flow rate ratio. The configuration parameters may comprise the size, 


\section{AL-QADISIYAH JOURNAL FOR ENGINEERING SCIENCES}

Vol. 10, No. 4

ISSN: $1998-4456$

geometry, and material of the pad and the cooler case. The effectiveness of DEC is determined experimentally by the saturation efficiency $\varepsilon$.

$$
\varepsilon=\frac{T_{\mathrm{db}, \mathrm{i}}-T_{\mathrm{db}, \mathrm{o}}}{T_{\mathrm{db}, \mathrm{i}}-T_{\mathrm{wb}, \mathrm{i}}}
$$

Where $T_{d b, i}$ is the intake air dry-bulb temperature (DBT), $T_{d b, o}$ is the outlet air $D B T$, and $T_{w b, i}$ is the air wet-bulb temperature (WBT) at inlet. The saturation efficiency is dependent on the difference between inlet $D B T$ and WBT which is defined as the wet-bulb depression. DEC method may not satisfy human thermal comfort criteria [1] when the wet-bulb depression is relatively small because the performance of DEC is affected by the weather condition [2]. Evaporative cooling can be also used as a pre-cooler [3], in a hybrid mode with air conditioning systems [4], and to enhance the condenser performance of refrigeration systems [5] and air cooled chillers [6]. The efficiency of the evaporative cooler is related to the ability of the pads to absorb water and to provide large contact area for heat and mass transfer between air and water. Thus, the efficiency of the cooler is mainly dependent on the pad type. Researcher pay considerable efforts to develop efficient pads made of local materials. Therefore, cooler pads may be fabricated from different materials such metal, wood straw, plastic [7], PVC sponge mesh [8], and coconut fiber [9]. In the recent years, rigid media cellulose (RMC) pads have been widely used as a cooling media for evaporation cooling because they are characterized by regular shape, compactness, wide range of types and geometries. The saturation efficiency can be also theoretically predicted by [10]

$$
\varepsilon=1-\exp \left[-\frac{h_{\mathrm{c}} A}{\dot{m}_{\mathrm{a}} C_{\mathrm{p}, \mathrm{a}}}\right]
$$

where $\dot{m}_{\mathrm{a}}$ is the mass flow rate of air, $h_{c}$ is the heat transfer coefficient, $A$ is the wetted surface area, and $C_{p, a}$ is the specific heat of humid air. For RMC pads, the following correlation can be used to calculate $h_{c}[11]$

$$
h_{\mathrm{C}}=0.1\left(\frac{l_{e}}{l}\right)^{0.12} \operatorname{Re}^{0.8} \operatorname{Pr}^{1 / 3}
$$

where I is the thickness of pad and $I_{c}$ is the characteristic length which is defined by

$$
I_{\mathrm{C}}=\frac{V}{A}
$$

and $V$ is the volume of RMC pad.

The objective of the present study is to investigate the performance of a direct evaporative cooler with $R M C$ pads under normal operating weather condition. The influence of air velocity is taken into 


\section{AL-QADISIYAH JOURNAL FOR ENGINEERING SCIENCES}

Vol. 10, No. 4

ISSN: $1998-4456$

consideration. The saturation efficiency of DEC with RMC pads is compared with that with wood straw pads of the same dimensions.

\section{EXPERIMENTAL SETUP}

The performance of direct evaporative cooler was experimentally measured using the experimental setup shown in Figure 1 and the experiments were achieved in the laboratories of Engineering College/Wasit University. This setup is mainly consisted of an evaporative cooler and a measuring system. The evaporative cooler was made of metal sheets in form of small box of size $(50 \times 50 \times 52) \mathrm{cm}^{3}$ with three removable doors. Each door contains $3 \mathrm{~cm}$ thickness $R M C$ pad of $(32 \times 32) \mathrm{cm}^{2}$ face area. The wetted area of pads is $539 \mathrm{~m}^{2}$ per unit volume and the inclination angle of air passages is about 42․ Figure 2 shows images for the investigated RMC and wood straw pads. A centrifugal fan was mounted inside the cooler box to draw ambient air through the RMC pads. For variable air velocity, the fan speed was controlled by a Pulse-Width-Modulation (PWM) electronic card of 500 Watt maximum power. A small electric submerged water pump circulates the water from the cooler sump to the upper edge of the pads. This enables cross contact between dripped water and the drawn air through the pads. A duct of square cross section of $(24 \times 24) \mathrm{cm}^{2}$ and $100 \mathrm{~cm}$ length was installed at the outlet of the cooler. Measured parameters were the DBT and WBT of air at inlet (ambient air) and at the outlet duct, water temperature of the cooler sump, and air velocity at the outlet duct. Volumetric water flow rate was kept constant during the experiments. The face air velocity of pads $U_{f}$ can be determined by:

$$
U_{\mathrm{f}}=U_{\mathrm{D}} \frac{A_{\mathrm{D}}}{A_{\mathrm{f}}}
$$

Where $U_{D}$ is the air velocity in the duct outlet, $A_{D}$ is the cross section area of the duct, and $A_{f}$ is the face area of pads.

Shielded thermistors NTC $10 K \Omega$ were used for temperature measurements. For the WBT, the thermistor was wrapped by a wetted cotton wick. An electronic sensor was used for air velocity measurements. This sensor operates with 5 Volts supply voltage while the output voltage of the sensor represents the air velocity. A formula was provided by the manufacturer to interpret the output voltage into air velocity. The sensors were installed as shown in Figure 1. A data logger Labjack T7 pro was used for the data acquisition with a user interface achieved by LabView software student edition 2011. For each experimental run, the steady state condition was observed. This can be ensured when the water temperature of the sump is being very close to the WBT of air. After reaching the steady state, 100 samples for each measured quantity are recorded by the data logger. 


\section{AL-QADISIYAH JOURNAL FOR ENGINEERING SCIENCES}

Vol. 10, No. 4

ISSN: 1998-4456

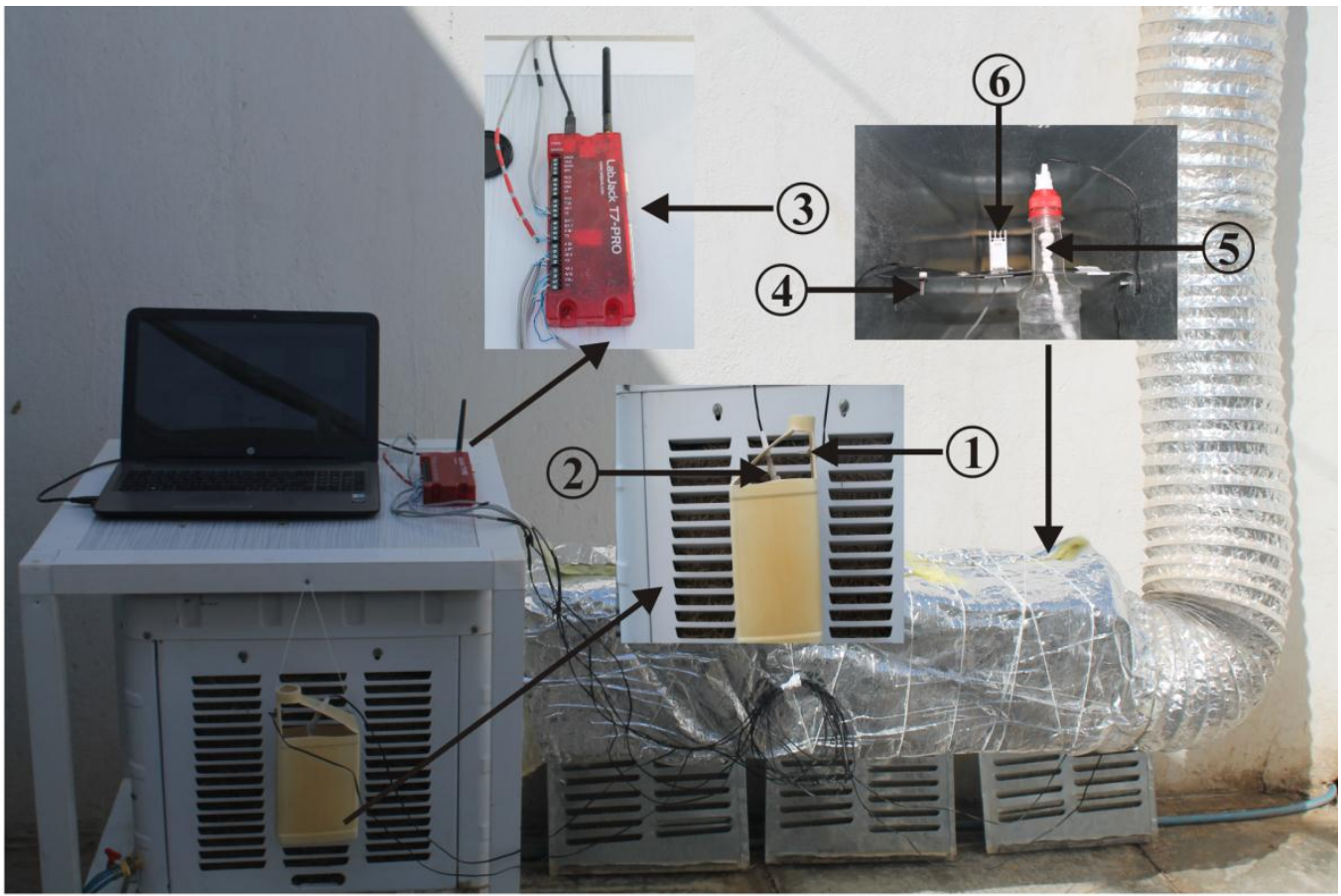

(1) Inlet air dry-bulb temperature sensor

(4) Outlet air dry-bulb temperature sensor

(2) Inlet air wet-bulb temperature sensor

(5) Outlet air wet-bulb temperature sensor

(3) Data logger Labjack T7 pro

(6) Outlet air velocity sensor

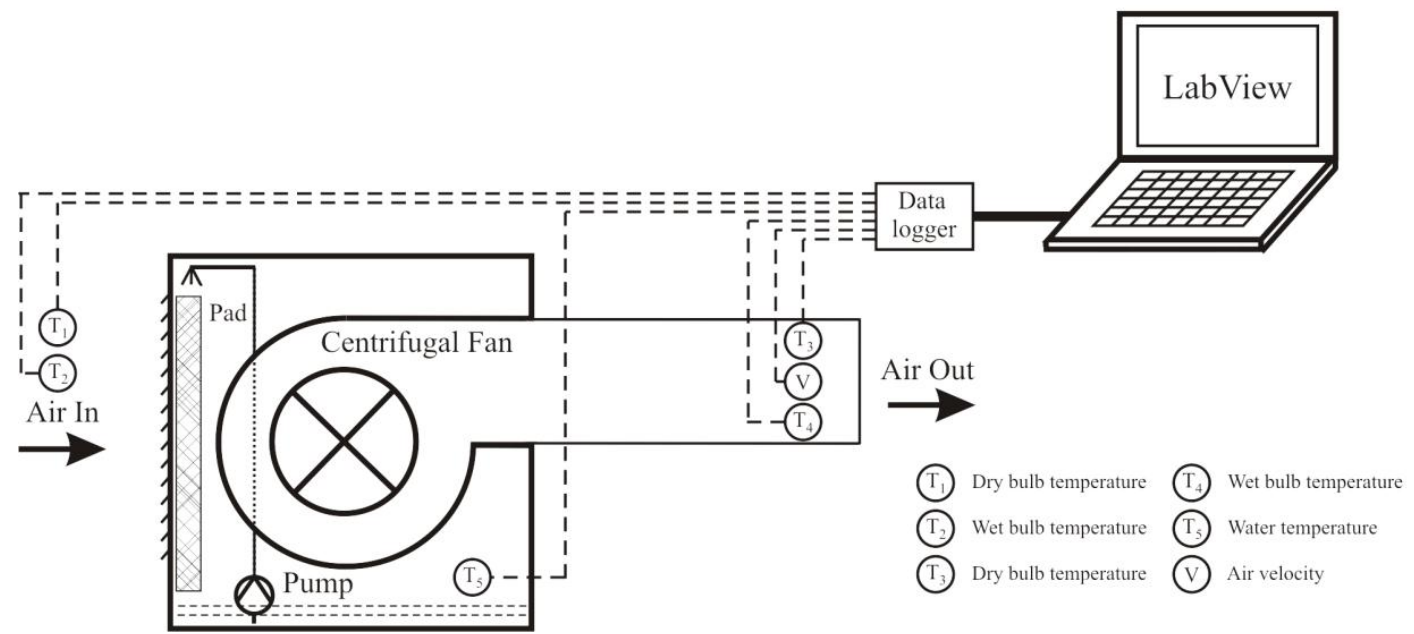

Figure 1: Experimental setup. 


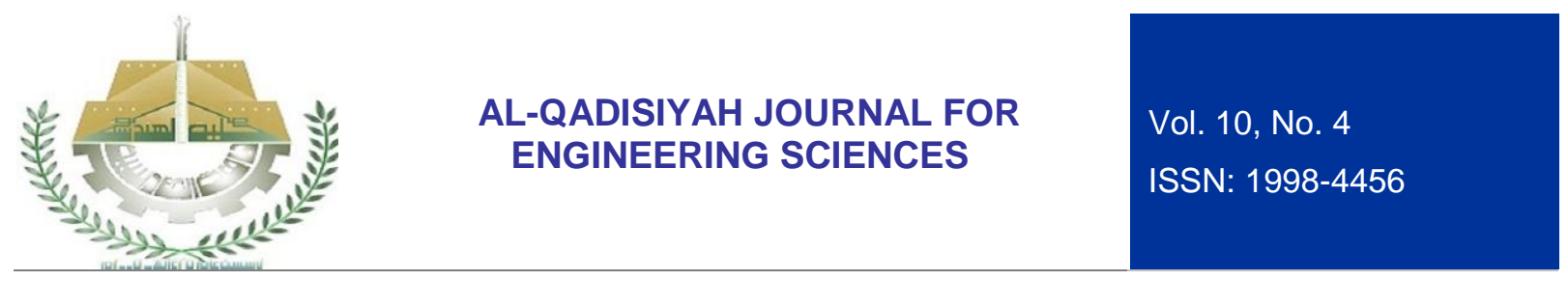

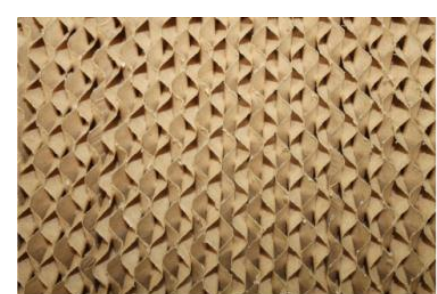

RMC pad

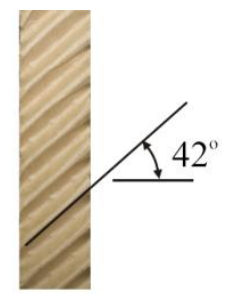

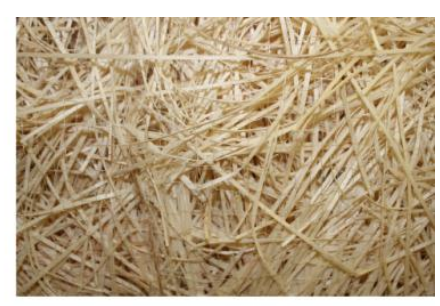

Wood straw pad

Figure 2: Images of RMC and wood straw pads.

The uncertainty in the saturation efficiency $U_{\varepsilon}$ is evaluated using the multi-samples uncertainty analysis method [12] which depends on the determination of systematic (fixed) and random errors for each measured quantity (measurand). Accordingly, $U_{\varepsilon}$ is determined by the following equation

$$
U_{\varepsilon}=\left[\sum_{j=1}^{n}\left(\frac{\partial \varepsilon}{\partial T_{j}} \delta T_{\mathrm{f}, \mathrm{j}}\right)^{2}+\sum_{\mathrm{j}=1}^{n}\left(\frac{\partial \varepsilon}{\partial T_{\mathrm{j}}} \delta T_{\mathrm{r}, \mathrm{j}}\right)^{2}\right]^{1 / 2}
$$

where $\delta T_{f, j}$ and $\delta T_{r, j}$ are systematic and random errors for temperature $T_{j}$, and $n$ is the number of temperatures. The saturation efficiency $\varepsilon$ can be considered to be a function of temperatures only, see Eq. (1). Then the sensitivity of $\varepsilon$ with respect to $T_{d b, i}, T_{d b, o}$, and $T_{w b, i}$ are expressed by

$$
\begin{gathered}
\frac{\partial \varepsilon}{\partial T_{\mathrm{db}, \mathrm{i}}}=\frac{T_{\mathrm{db}, \mathrm{o}}-T_{\mathrm{wb}, \mathrm{i}}}{\left(T_{\mathrm{db}, \mathrm{i}}-T_{\mathrm{wb}, \mathrm{i}}\right)^{2}} \ldots(7) \\
\frac{\partial \varepsilon}{\partial T_{\mathrm{db}, \mathrm{o}}}=\frac{-1}{T_{\mathrm{db}, \mathrm{i}}-T_{\mathrm{wb}, \mathrm{i}}} \ldots(8)
\end{gathered}
$$

and

$$
\frac{\partial \varepsilon}{\partial T_{\mathrm{wb}, \mathrm{i}}}=\frac{T_{\mathrm{db}, \mathrm{i}}-T_{\mathrm{db}, \mathrm{o}}}{\left(T_{\mathrm{db}, \mathrm{i}}-T_{\mathrm{wb}, \mathrm{i}}\right)^{2}}
$$

The random error can be determined for each parameter by the following equation [12]

$$
\delta T_{\mathrm{r}}=\frac{2 S}{\sqrt{m}}
$$

where $S$ is the standard deviation of the recorded samples and $m$ is the number of samples. For a confidence level of $95 \%$, the value of $m$ corresponds to 100 samples according to the " $t$ " table. The systematic error is, equal to $1 \%$, provided by the manufacturer of the thermistors. The uncertainty limit in the temperature measurements and air velocity were $\pm 0.5^{\circ} \mathrm{C}$ and $\pm 11.6 \%$, respectively. The saturation efficiency 


\section{AL-QADISIYAH JOURNAL FOR ENGINEERING SCIENCES}

Vol. 10 , No. 4

ISSN: $1998-4456$

was very sensitive to the change in the WBT compared to DBT. This can be shown by Eq. (9) where the WBT exists only in denominator and the difference between DBT and WBT is squared leading to a significant influence on the results when WBT changes. For the saturation efficiency, the uncertainty limit of the experimental data was $\pm 4.5 \%$.

\section{RESULTS AND DISSCUSION}

In this study, the saturation efficiency of DEC was experimentally investigated with RMC pads. Time change of temperatures for air and water were recorded. The impact of air velocity and wet-bulb depression on the saturation efficiency was investigated. A comparison was made between experimental and predicted data. In addition, the saturation efficiency with RMC pads was compared with that of wood straw pads.

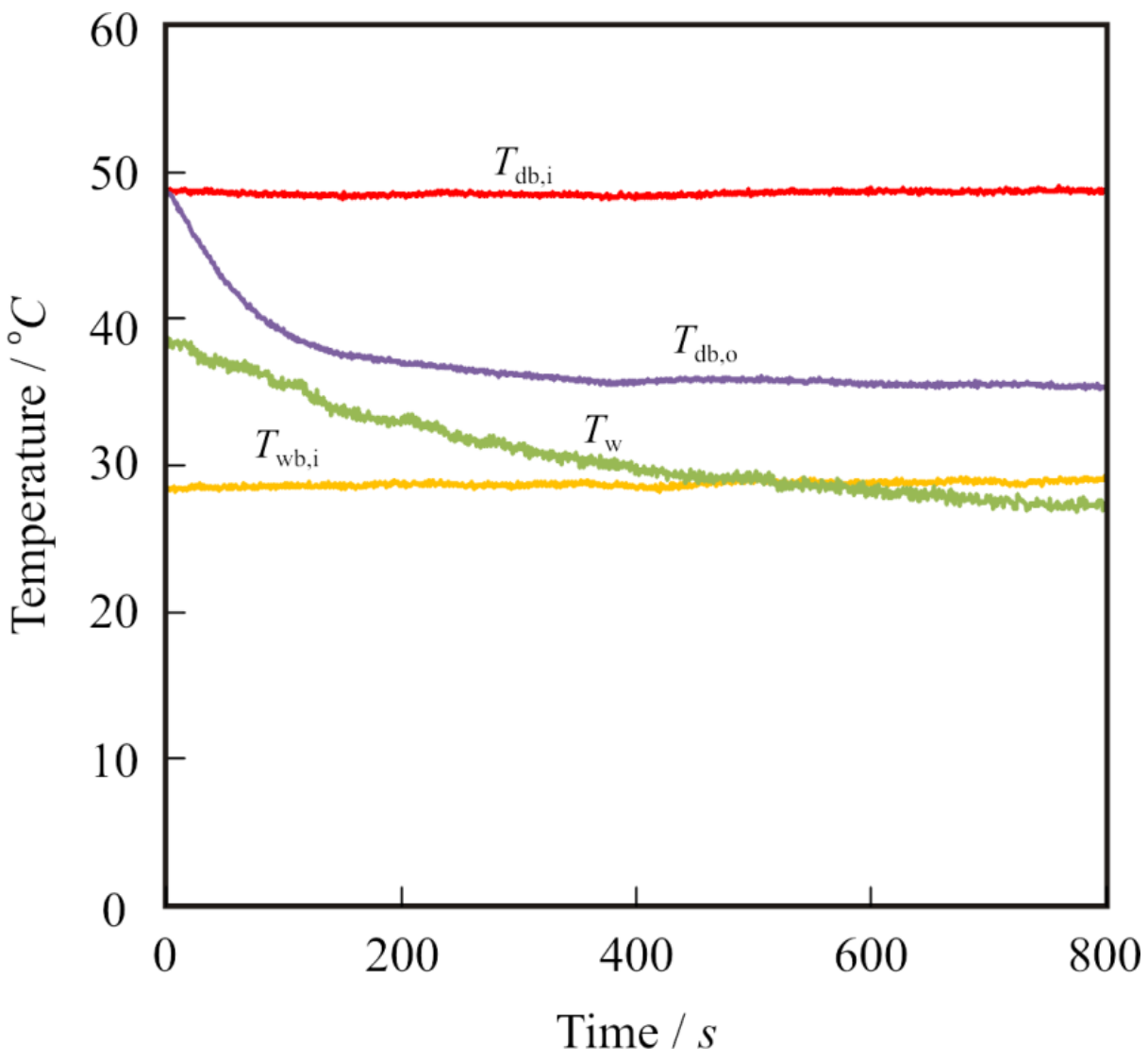

Figure 3: Time change of temperatures.

Figure 3 shows the time change of intake (ambient) DBT and WBT ( $T_{d b, i}$ and $\left.T_{w b, i}\right)$, water temperature $\left(T_{w}\right)$, and the outlet $D B T\left(T_{d b, o}\right)$. The water volumetric flow rate and the face air velocity of pads were 1.7 lit $\cdot \mathrm{min}^{-1}$ and is $1.2 \mathrm{~m} \cdot \mathrm{s}^{-1}$ respectively. The change in the ambient temperatures was relatively small during this experiment. The outlet DBT decreases sharply with the time until it approaches the steady state condition where the change in the temperature with time becomes very small. The water temperature decreases also with time but with a slower rate than the outlet air. Therefore the time required to reach the steady state for water $\left(T_{w}\right)$ is longer compared to that for the outlet $D B T\left(T_{d b, o}\right)$. This time period is dependent on the water amount in the cooler sump. At steady state, the WBT is higher than the water temperature. This 


\section{AL-QADISIYAH JOURNAL FOR ENGINEERING SCIENCES}

Vol. 10 , No. 4

ISSN: $1998-4456$

may due to the parasitic heat transfer from ambient to wet-bulb sensor which increases the sensor reading [13]. However, the difference is within the uncertainty limit of the temperate measurements.

The time change of the measured saturation efficiency $(\varepsilon)$ is shown in Figure 4.The value of $\varepsilon$ was determined using Eq. (1). At time equals zero, the pad was completely dry. The adiabatic efficiency increases linearly with time, then the rate of increase slows gradually, and finally reaches to the steady state condition. The time response of $\varepsilon$ is close to the exponential form. The saturation efficiency reached $71 \%$ of the maximum value in 100 seconds and the final steady state saturation efficiency was reached after 600 seconds.

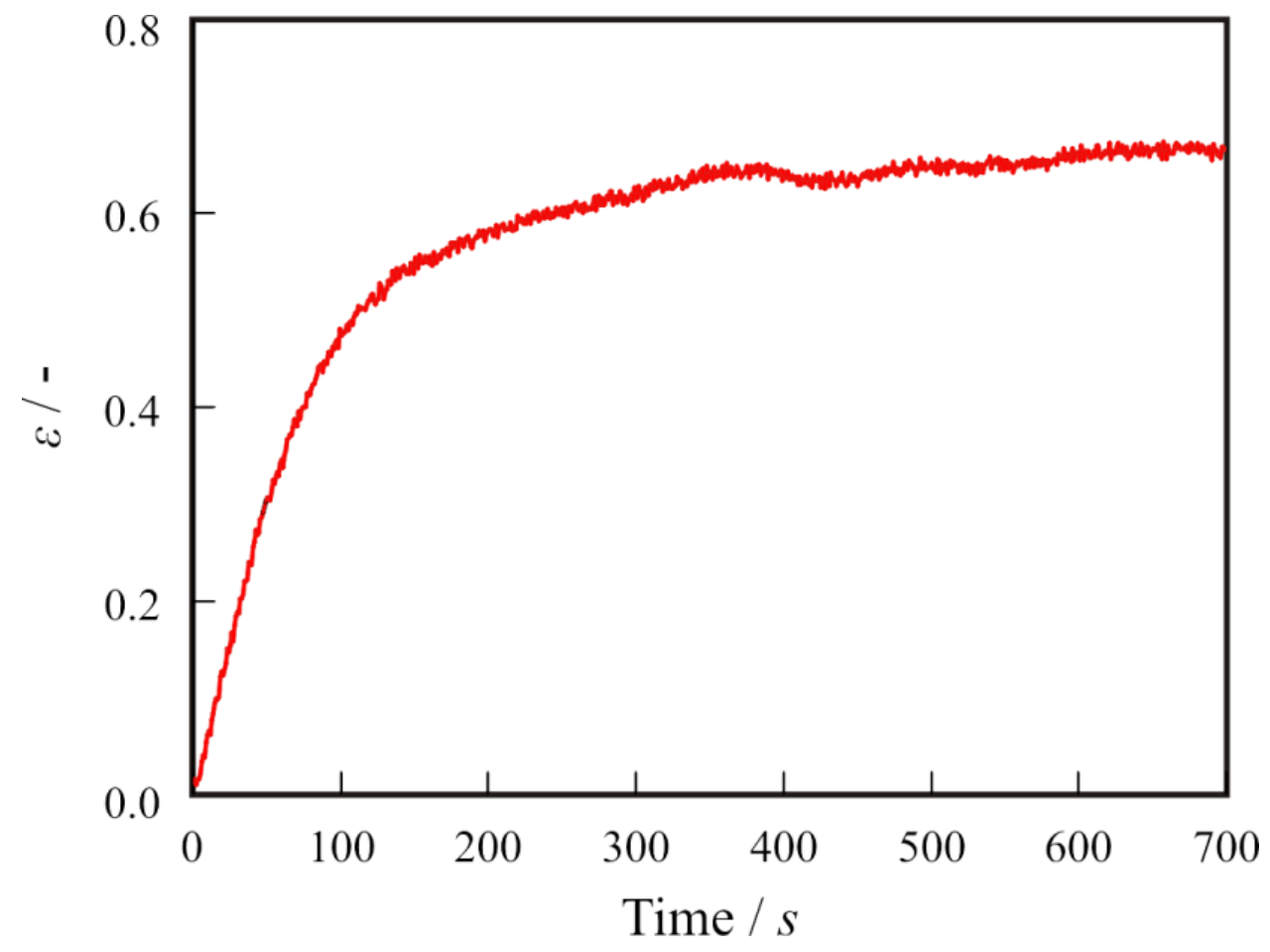

Figure 4: The saturation efficiency as a function of wet-bulb depression. 


\section{AL-QADISIYAH JOURNAL FOR ENGINEERING SCIENCES}

Vol. 10 , No. 4

ISSN: $1998-4456$

The performance of DEC with wood straw and RMC pads was experimentally investigated. Air velocity in the outlet duct was varied between 2 and $13 \mathrm{~m} \cdot \mathrm{s}^{-1}$. This range corresponds to face velocity on the pads between 0.5 and $3.0 \mathrm{~m} \cdot \mathrm{s}^{-1}$. The face air velocity is determined using the air volumetric flow rate with the face area of pads. The ambient DBT was between 35.5 and $33^{\circ} \mathrm{C}$. During the experiments, the WBT was between $20^{\circ} \mathrm{C}$ and $19.2^{\circ} \mathrm{C}$. Figure 5 shows a comparison between experimental and predicted saturation efficiency as a function of air face velocity for RMC pads. The experimental data were determined using Eq. (1) while the predicted values were based on Eq. (2). The saturation efficiency decreases with the increase in the air velocity. This may be because of the increase in the inlet mass flow rate of air which results in a decrease in the moisture fraction in the outlet air, and then increasing the outlet DBT. Experimental data are higher than predicted one for all experimental runs. This may be a result of assumptions that was previously made for Eq. (2) that ignored the effect of latent heat of water evaporation. However, Eq. (2) underestimated the saturation efficiency by about $18 \%$ for the measured range of air velocity.

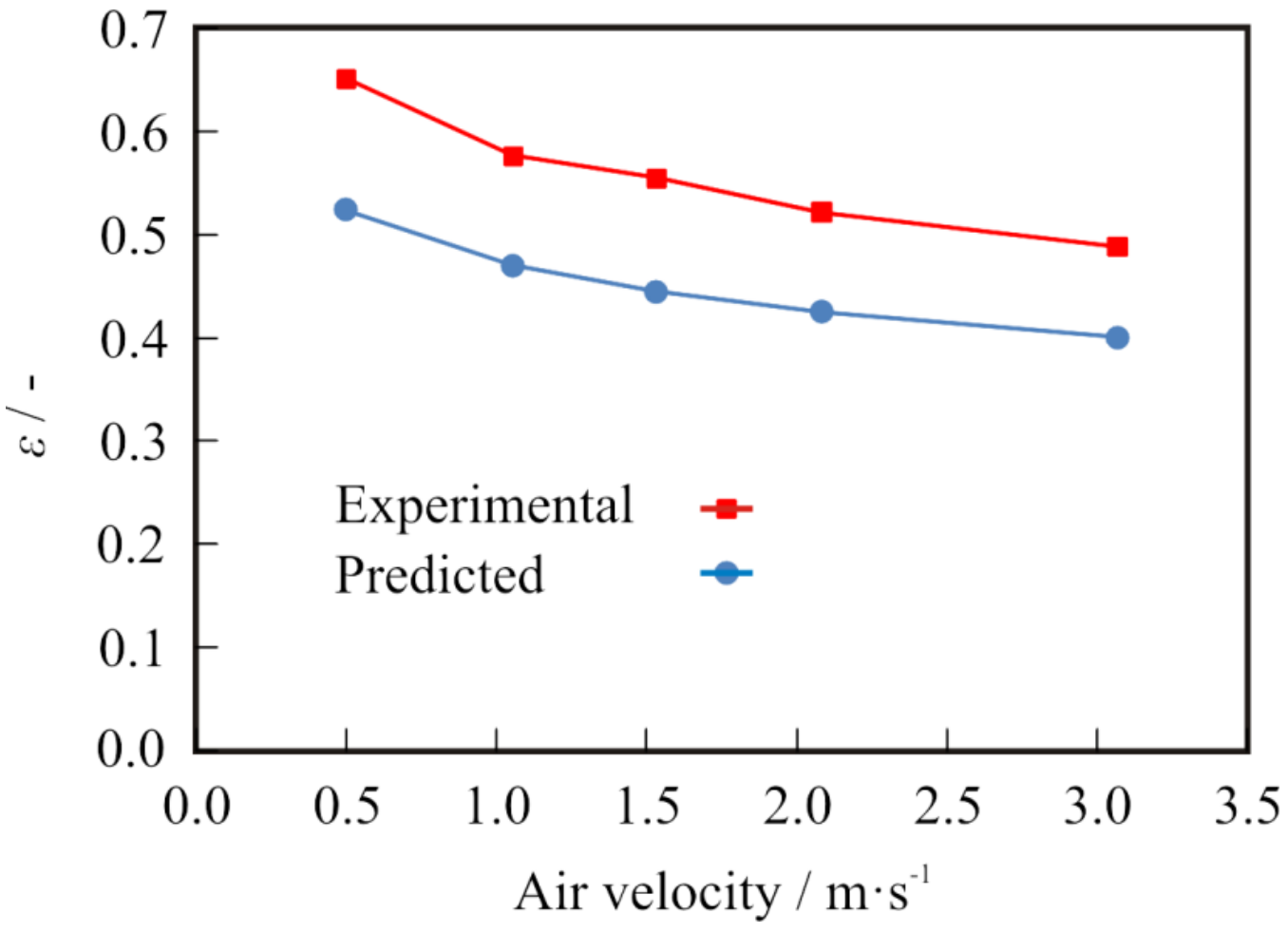

Figure 5: Comparison between experimental and predicted saturation efficiency versus air velocity for RMC pads. 


\section{AL-QADISIYAH JOURNAL FOR ENGINEERING SCIENCES}

Vol. 10 , No. 4

ISSN: $1998-4456$

Figure 6 shows the saturation efficiency of DEC as a function of face air velocity for RMC and wood straw pads. The saturation efficiency of DEC with wood straw pads is higher than that with RMC pads for the air velocity range between 0.5 and $3.0 \mathrm{~m} \cdot \mathrm{s}^{-1}$. For low velocity, the evaporative cooler performance is slightly affected by the pad type. For all data points, wood straw pads are more efficient than RMC pads. This may due to differences in material specifications such as the ability of material to absorb water. The effectiveness of pads is mainly dependent on the ability of pad material to absorb water and to mix both water and air together for exchanging heat and water vapor. However, this is also affected by the pad's thickness. For the present study, the RMC pad thickness is only $3 \mathrm{~cm}$ which is close to the thickness of wood straw pads.

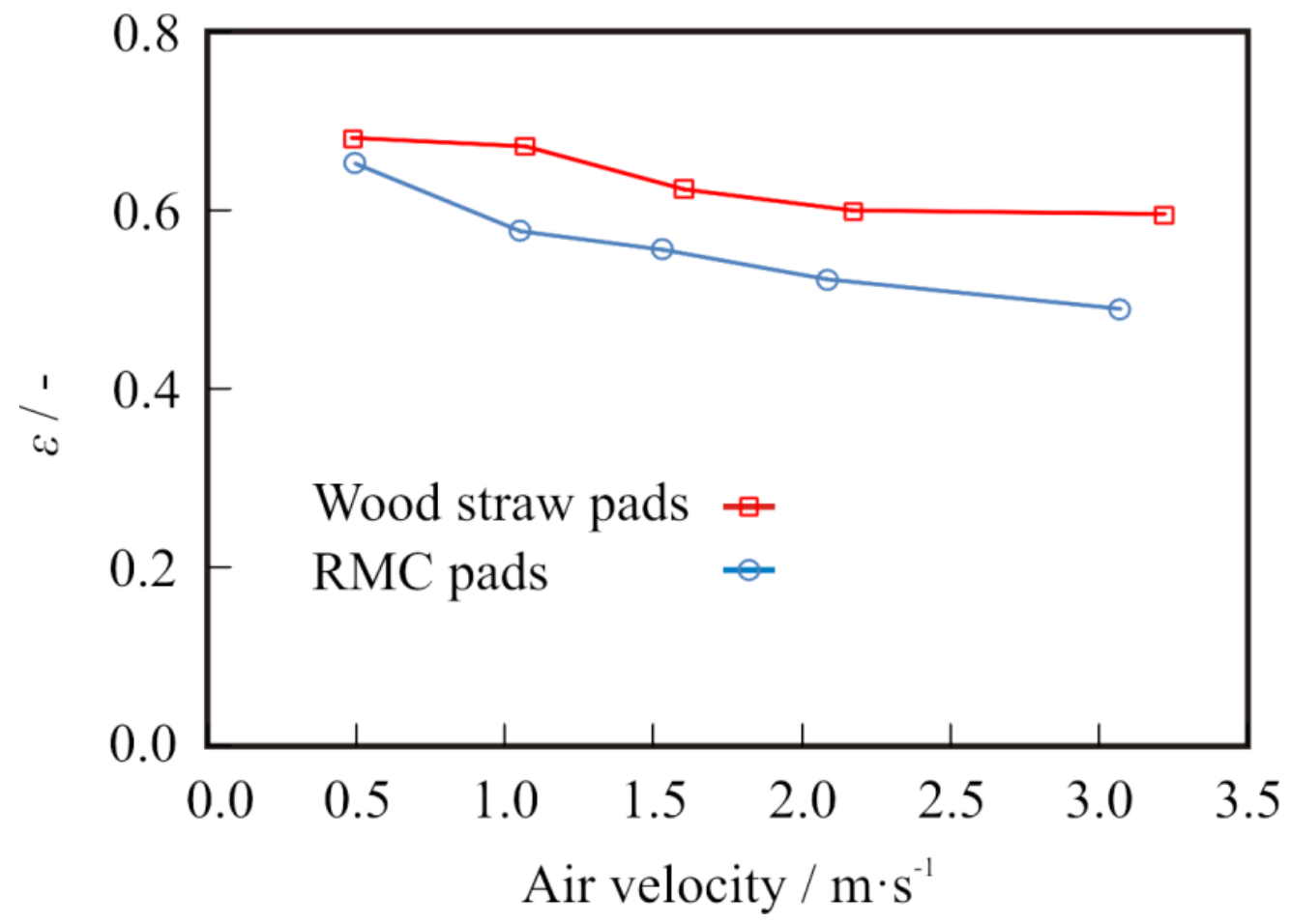

Figure 6: Experimental saturation efficiency versus air velocity for wood straw and RMC pads. 


\section{AL-QADISIYAH JOURNAL FOR ENGINEERING SCIENCES}

Vol. 10 , No. 4

ISSN: $1998-4456$

\section{CONCLUSIONS}

The saturation efficiency of direct evaporative cooling (DEC) was experimentally investigated with RMC pads and compared with that of wood straw pads. Face air velocity was varied between 0.5 and 3.0 $m \cdot s^{-1}$. Transient temperature change and the saturation efficiency were recorded using a data acquisition system. From this study, it could be shown that the saturation efficiency reached $71 \%$ of its steady state value in the first $100 \mathrm{~s}$ and the final steady state value was reached after $600 \mathrm{~s}$. Eq. (2) [10] underestimated the effectiveness by about $18 \%$ for the measured range of air velocity. The saturation efficiency decreases with the increase in the air velocity. The effectiveness of DEC with wood straw pads was higher than that with $R M C$ pads of the same dimensions.

\section{LIST OF SYMBLOS}

\begin{tabular}{|c|c|}
\hline & \\
\hline$A$ & area, $m^{2}$ \\
\hline$C_{p}$ & specific heat, $\mathrm{kJ} \cdot \mathrm{kg}^{-1} \cdot \mathrm{K}^{1}$ \\
\hline I & pad thickness, $m$ \\
\hline$I_{c}$ & characteristic length, $m$ \\
\hline$\dot{m}$ & mass flow rate, $\mathrm{kg} \cdot \mathrm{s}^{-1}$ \\
\hline $\operatorname{Pr}$ & Prandtl number \\
\hline$R e$ & Reynolds number \\
\hline$S$ & Standard deviation \\
\hline$T$ & temperature, $\mathrm{K}$ \\
\hline$U$ & Uncertainty \\
\hline V & pad volume, $m^{3}$ \\
\hline Gree & \\
\hline$\varepsilon$ & saturation efficiency \\
\hline Subs & \\
\hline$d b$ & $d r y$-bulb \\
\hline$D$ & duct \\
\hline$f$ & face area of pads \\
\hline$i$ & inlet \\
\hline 0 & outlet \\
\hline$w$ & water \\
\hline$w b$ & wet-bulb \\
\hline Abbr & \\
\hline$D E C$ & Direct Evaporative Cooling \\
\hline$D B T$ & Dry-Bulb Temperature \\
\hline$R M C$ & Rigid Media Cellulose \\
\hline WBT & Wet-Bulb Temperature \\
\hline
\end{tabular}

\section{BIODATA}

Dr. Alaa Ruhma Al-Badri studied the PhD (Dr. -Ing.) at the Erlangen-Nuremebrg University (Germany), lecturer at the Engineering College / Wasit University. Research intersts include refrigeration and air conditioning, heat engineering and solar systems. 


\section{AL-QADISIYAH JOURNAL FOR ENGINEERING SCIENCES}

Vol. 10 , No. 4

ISSN: $1998-4456$

\section{REFRENCES}

1. J.R. Camargoa, C.D. Ebinumab, S. Cardosoa, Three Methods to Evaluate the Use of Evaporative Cooling for Human Thermal Comfort, Engenharia Térmica (Thermal Engineering), 5 (2006 ) 09-15.

2. J.M. Wu, X. Huang, $\boldsymbol{H}$. Zhang, Theoretical analysis on heat and mass transfer in a direct evaporative cooler, Applied Thermal Engineering, 29(5-6) (2009) 980-984.

3. Y. Chen, H. Yang, Y. Luo, Parameter Sensitivity Analysis of Indirect Evaporative Cooler (IEC) with Condensation from Primary Air, Energy Procedia, 88 (2016) 498-504.

4. V. Jain, S.C. Mullick, T.C. Kandpal, A financial feasibility evaluation of using evaporative cooling with air-conditioning (in hybrid mode) in commercial buildings in India, Energy for Sustainable Development, 17(1) (2013) 47-53.

5. P. Martínez, J. Ruiz, C.G. Cutillas, P.J. Martínez, A.S. Kaiser, M. Lucas, Experimental study on energy performance of a split air-conditioner by using variable thickness evaporative cooling pads coupled to the condenser, Applied Thermal Engineering, 105 (2016) 1041-1050.

6. X. Hao, C. Zhu, Y. Lin, H. Wang, G. Zhang, Y. Chen, Optimizing the pad thickness of evaporative aircooled chiller for maximum energy saving, Energy and Buildings, 61 (2013) 146-152.

7. A. Malli, H.R. Seyf, M. Layeghi, S. Sharifian, H. Behravesh, Investigating the performance of cellulosic evaporative cooling pads, Energy Conversion and Management, 52(7) (2011) 2598-2603.

8. C.-M. Liao, K.-H. Chiu, Wind tunnel modeling the system performance of alternative evaporative cooling pads in Taiwan region, Building and Environment, 37(2) (2002) 177-187.

9. J.K. Jain, D.A. Hindoliya, Experimental performance of new evaporative cooling pad materials, Sustainable Cities and Society, 1(4) (2011) 252-256.

10. J.R. Camargo, C.D. Ebinuma, J.L. Silveira, Experimental performance of a direct evaporative cooler operating during summer in a Brazilian city, International Journal of Refrigeration, 28(7) (2005) 11241132.

11. J.A. Dowdy, N.S. Karabash, Experimental determination of heat and mass transfer co-efficients in rigid impregnated cellulose evaporative media, ASHRAE Transaction, 93 (Part 2) (1987) 382-395.

12. R.J. Moffat, Describing the uncertainties in experimental results, Experimental Thermal and Fluid Science, 1(1) (1988) 3-17.

13. J.P. Brenner, Design Specifications for Wet-Bulb Aspirator Apparatus, Master Thesis, University of Wisconsin-Madison, 2010. 